WellBeing International

WBI Studies Repository

1984

\title{
Attitudes Toward Animals: Age-Related Development Among Children
}

Stephen R. Kellert

Yale University

Follow this and additional works at: https://www.wellbeingintlstudiesrepository.org/acwp_sata

Part of the Animal Studies Commons, Other Anthropology Commons, and the Social Psychology and Interaction Commons

\section{Recommended Citation}

Kellert, S.R. (1984). Attitudes toward animals: Age-related development among children. In M.W. Fox \& L.D. Mickley (Eds.), Advances in animal welfare science 1984/85 (pp. 43-60). Washington, DC: The Humane Society of the United States.

This material is brought to you for free and open access by WellBeing International. It has been accepted for inclusion by an authorized administrator of the WBI Studies Repository. For more information, please contact wbisr-info@wellbeingintl.org.

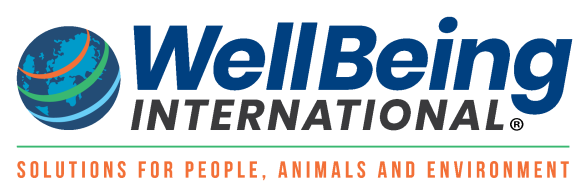




\section{ATTITUDES TOWARD ANIMALS: AGE-RELATED DEVELOPMENT AMONG CHILDREN*}

\section{Stephen R. Kellert**}

School of Forestry and Environmental Studies, Yale University

New Haven, Connecticut 06511

\section{Abstract}

This paper reviews the results of a study of 267 children in the 2nd, 5th, 8th, and 11th grades. A battery of tests was used to examine children's knowledge and attitudes towards animals, and behavioral contacts with animals. A typology of basic attitudes towards animals and appropriate scales was employed. Children's knowledge and attitudes towards animals were also compared to those of adults 18 years of age and over. Major differences occurred among children distinguished by age, sex, ethnicity, and urban/rural residence. Additionally, significant knowledge and attitude variations occurred among diverse animal-related activity groups (e.g., among children who hunted, birdwatched, learned about animals in school). Perhaps the most important finding was the identification of three stages in the development of children's perceptions of animals. The transition from

*This study was funded by grants from the U.S. Fish and Wildlife Service and G.R. Dodge Foundation. For details of Dr. Kellert's earlier and more extensive study of American attitudes toward and knowledge of animals, see Appendix.

**Many thanks to Miriam Westervelt who co-authored the U.S. Fish and Wildlife Service, General Printing Office report \#024-010-00641-2 of the children's study. 
6 to 9 years of age primarily involved major changes in affective, emotional relationships to animals. The change from 10 to 13 years of age was marked by a major increase in cognitive, factual understanding and knowledge of animals. The shift from 13 to 16 years of age witnessed a dramatic broadening in ethical concern and ecological appreciation of animals and the natural environment.

\section{INTRODUCTION}

This report is the fifth in a series of studies on American attitudes, knowledge and behaviors toward animals and natural habitats. The first three reports focused on the findings of a national survey of 3, 107 adult Americans residing in the 48 contiguous states and Alaska (Kellert 1979, 1980a; Kellert and Berry 1981). The fourth report considered historical trends in American animal use and perception during the twentieth century (Kellert and Westervelt 1982). This fifth report focuses on children's attitudes, knowledge and behaviors toward animals.

Children's perceptions of animals, particularly very young children, are especially difficult to study (Pomerantz 1977). This study should, therefore, be regarded as exploratory, preliminary and tentative. Because of its exploratory character, this study did not include a random sample of American children. The sample was instead confined to the state of Connecticut, although representative numbers of children from each age, sex, urban/rural, and black/white category were included. The total sample included 63 second, 68 fifth, 67 eighth, and 69 eleventh grade students: a total of 267 children. Because somewhat similar methodologies were employed in the study of adult Americans, the children's sample will at times be compared with results obtained in the national adult survey.

\section{KNOWLEDGE OF ANIMALS}

Knowledge of animals was assessed primarily in four ways: a series of 33 true/false and multiple choice questions, a pictorial identification test of 15 animals, 11 questions regarding the primary foods of selected animals, and a film test focusing on ecological relationships.

The results generally indicated that most children possessed a limited knowledge of animals. For example, less than $30 \%$ of the children were aware that the spring peeper is a frog, and only $29 \%$ knew koala bears are not really bears. A disappointing $21 \%$ understood veal does not come from lamb, and $55 \%$ believed whales are a large fish. A better but disappointing $60 \%$ realized all birds do not fly south for the winter, but only $52 \%$ knew the penguin is a bird, just $26 \%$ knew a tern 
is not an insect, and only $29 \%$ realized tigers do not live in Africa.

Lack of ecological understanding was suggested by responses to the film testing segment. Most children interpreted predation and nutrient cycling in anthropomorphic and negative terms, rarely appreciating or identifying the ecological values of these activities. The efforts of dung beetles were generally considered "disgusting," and many children regarded predation as "wrong."

However, some encouraging knowledge results did emerge. Children as a whole, and 11th graders in particular, were significantly more knowledgeable than adults on questions concerning invertebrates and the basic biological characteristics of animals (Table 1). Adults were, however, more knowledgeable than children about domestic animals and situations involving animals inflicting injury on people and property. Greater knowledge of invertebrates among children was suggested by $78 \%$ of all children and $86 \%$ of 11 th graders, compared to $50 \%$ of adults, knowing spiders do not have 10 legs. When adults were compared with 11 th graders only, $23 \%$ of adults versus $48 \%$ of the students knew inch worms are not in the same family as earth worms.

Table 1. Mean correct score by types of knowledge questions

\section{Children's and adult samples}

\begin{tabular}{lccc}
\hline & $\begin{array}{c}\text { All children } \\
\text { (<18 years of age) }\end{array}$ & $\begin{array}{c}\text { 11th } \\
\text { grade }\end{array}$ & $\begin{array}{c}\text { Adult } \\
\text { (<18 years of age) }\end{array}$ \\
\hline Biological characteristics & 56.8 & 63.9 & 55.3 \\
Invertebrates & 47.5 & 51.3 & 34.7 \\
Human injury & 39.5 & 47.8 & 63.4 \\
Domestic animals & 39.2 & 44.4 & 53.4 \\
Taxonomic characteristics & 37.3 & 43.9 & 38.5 \\
Endangered species & 24.6 & 24.6 & 27.4 \\
& & & \\
\hline
\end{tabular}

Based on mean scores, children were most knowledgeable about the basic biological characteristics of animals (e.g., "snakes are covered by a thin layer of slime") and invertebrates. These knowledge question categories had overall mean scores, respectively, of 56.8 and 47.5, on a scoring range from 0 to 100 . Adults had a dramatically lower invertebrate question mean score of 34.7. The adults, however, obtained a significantly higher mean score on questions concerning human injury or property damage-63.4 versus a children's mean of 39.5 . Both children 
and adults had similar scores on the "taxonomic characteristics of animals" category (e.g., "koala bears are not really bears")-37.3 and 38.5 respectively. Both groups possessed relatively little knowledge of endangered species.

Children were relatively able to recognize a variety of animal species. At least $85 \%$ correctly identified a bluejay, swan, rattlesnake, eagle, raccoon, dolphin, wolf and monarch butterfly. Almost threequarters correctly identified a duck, although only $28 \%$ recognized it as a mallard duck. On the other hand, only $8 \%$ could identify a great blue heron, just one-third recognized a duck-billed platypus, and only $15 \%$ knew a bobwhite.

Children were also knowledgeable about the primary foods of a variety of species. Most children knew what foods were mainly eaten by mice, rabbits, wolves, owls, robins, caterpillers, snakes, and frogs. Only a minority, however, knew which foods were primarily consumed by trout, deer, and bobcats.

Highly significant knowledge scale differences occurred among children distinguished by age, ethnicity, and geographic place of residence. Male/female differences were also significant but at a more modest .02 confidence level (Table 2). Eleventh grade children had the

Table 2. Analysis of variance and multiple classification results on knowledge scale among age, sex, ethnic and urban/rural groups

\begin{tabular}{|c|c|c|}
\hline Sig F & $\overline{\mathrm{X}}$ score & $\begin{array}{l}\text { Deviation from grand mean } \\
\text { after adjusting for independent } \\
\text { and covariate variables }\end{array}$ \\
\hline
\end{tabular}

\section{Age}

2nd grade

5 th grade

8 th grade

11 th grade

Sex

Male

Female

Ethnicity

White

Nonwhite

Urban/rural

Urban

Small city

Suburb

Rural
.00

.02

.00 
highest mean scores; 2nd graders, the lowest. Relatively high knowledge scores occurred among rural children and 8th graders. In contrast, relatively low knowledge means were characteristic of black children and children residing in large cities.

Age distinctions were especially impressive. Knowledge scale differences among 8th and 11th graders, however, were substantially less divergent than between 5th and 8th graders, suggesting a decline in the effect of age. An absence of knowledge scale differences among adults over 18 years of age further suggested decreasing importance of age on knowledge of animals.

Ethnic differences were very striking, particularly the very low knowledge scores of nonwhites. Black children had the lowest knowledge scores of any demographic group with the exception of 2nd graders. These knowledge scale differences remained after considering the possible confounding effects of other demographic variables, particularly urban/rural residence.

Urban/rural differences were very significant, particularly when comparing children living in large cities with those residing in the most rural areas. Rural children had the second highest knowledge scale scores, in contrast to children residing in large cities, who had the third lowest scores.

Male/female differences were less pronounced, although still significant at the .02 level. Significantly higher male knowledge scores typically occurred when the animal was a predator. Species preference results also revealed a more negative view of predator animals among female children.

\section{ATTITUDES TOWARD ANIMALS}

A typology of basic attitudes toward animals was developed during previous research on adult relationships to animals. Brief definitions of nine attitude types are indicated in Table 3, although more thorough descriptions are available elsewhere (Kellert 1980b). Survey scales were developed to measure each of the attitudes, although it proved impossible to obtain an adequate aesthetic scale. Fifty-four questions were used for measuring the eight attitude scales. Additionally, a 30-minute film, and an accompanying 87-item questionnaire, were created to provide a less structured and more visually sensitive test of attitudes toward animals. Approximately 70 films were reviewed to obtain appropriate segments for this film methodology. The relative independence of the eight attitude scales was suggested by scale intercorrelations of .30 and less with the exception of the 
Table 3. Attitudes toward animals

Naturalistic:

Ecologistic:

Humanistic:

Moralistic:

Scientistic:

Aesthetic:

Utilitarian:

Dominionistic:

*Negativistic:
Primary interest and affection for wildlife and the outdoors.

Primary concern for the environment as a system, for interrelationships between wildlife species and natural habitats.

Primary interest and strong affection for individual animals, principally pets.

Primary concern for the right and wrong treatment of animals, with strong opposition to exploitation or cruelty toward animals.

Primary interest in the physical attributes and biological functioning of animals.

Primary interest in the artistic and symbolic characteristics of animals.

Primary concern for the practical and material value of animals or the animal's habitat.

Primary interest in the mastery and control of animals typically in sporting situations.

Primary orientation an active avoidance of animals due to indifference, dislike or fear.

*Hypothetically, the negativistic attitude can be divided into two attitude types: neutralistic attitude reflecting a passive avoidance of animals due to indifference; and, a negativistic attitude characterized by dislike and fear of animals. In this research, only one encompassing attitude has been considered.

negativistic and naturalistic, and negativistic and ecologistic attitudes, which correlated at the +.48 level.

The relative occurrence of the attitudes was assessed by examining attitude scale score frequency distributions, the slope of the regression line of the frequency distributions, and standardized attitude scale mean scores. According to these indicators, the most common attitude was the humanistic (Figure 1). This attitude scale had the highest mean score, lowest slope figure (indicative of a more dispersed frequency distribution), and included more children in the higher scoring ranges. Also indicative of the relative "popularity" of the humanistic attitude was the finding of "loveable animals" as the most preferred type of animal, cited by $39 \%$ of the children (Table 4). In general, strong emotional attachment to individual animals, and a tendency toward anthropomorphism, were the most typical perceptions of animals among the children studied.

The second and third most frequent attitudes were the naturalistic and negativistic. These attitudes were negatively correlated, suggesting two somewhat conflicting perspectives of animals as common among children. The relative "popularity" of the naturalistic perspective was also suggested by "animals in the woods" as the second most 
Figure 1: Frequency distributions and mean scores of attitude scales, children

\section{FREQUENCY DISTRIBUTIONS AND MEAN SCORES OF ATTITUDE SCALES, CHILDREN}
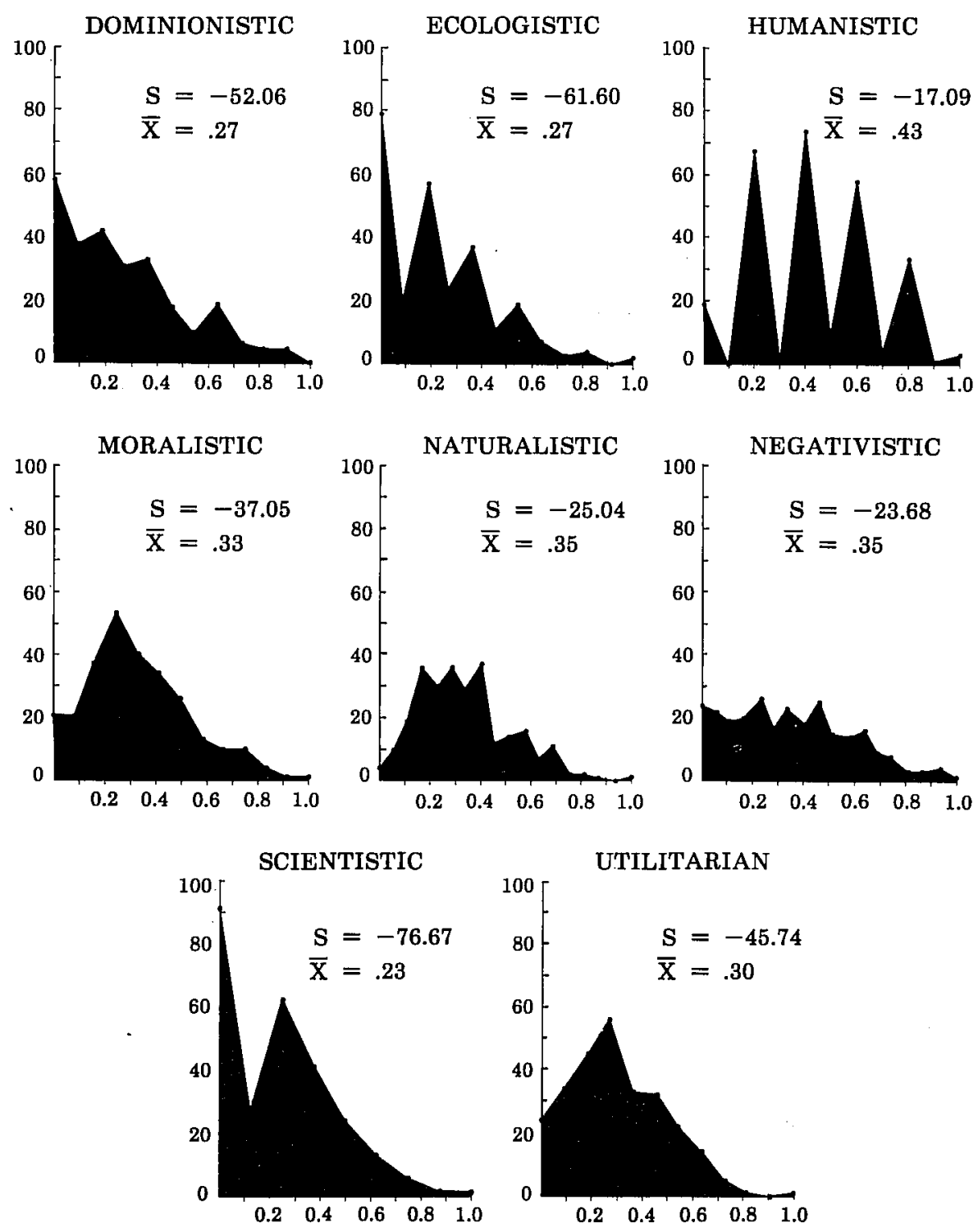
Table 4. Type of animal liked the most by all children

Beautiful animals

$11.7 \%$

Useful animals

$8.8 \%$

Animals that scientists study

$5.6 \%$

Loveable animals

$38.8 \%$

Animals in sports

$9.1 \%$

Animals in the woods

$22.8 \%$

Animals that are important to the balance of nature

preferred type of animal, cited by $23 \%$ of the children.

The moralistic attitude ranked fourth in overall frequency of occurrence. Concern for the ethical treatment of animals was indicated by $70 \%$ of the children objecting to harvesting wild animals for their fur. Additionally, only $26 \%$ of the children supported hunting for recreational or sporting purposes, and $91 \%$ objected to trophy hunting, although $60 \%$ approved of hunting for food.

The utilitarian attitude was fifth in relative "popularity." By comparison, the greater frequency of the humanistic and naturalistic attitudes suggested children appreciate animals more for recreational and emotional than for practical reasons. Only $9 \%$ of the children cited "useful" animals as their favorite type of animal.

The dominionistic attitude was relatively uncommon, ranking sixth in frequency of occurrence. The least requently occurring attitudes were the ecologistic and scientistic. These latter attitudes emphasize an intellectual perspective of animals, suggesting that conceptual understandings of animals are somewhat uncommon among children. The rarity of the scientistic and ecologistic attitudes was also reflected in "scientifically interesting animals" being cited by $6 \%$, and animals "important to the balance of nature" by $4 \%$, of the children as their favorite types of animals.

In the national study of adults, the humanistic attitude was also the most frequent perspective of animals, and the negativistic and moralistic attitudes were similarly popular (Table 5). The most striking difference in attitudes towards animals between children and adults was the widely varying occurrence of the naturalistic and utilitarian perspectives. The naturalistic attitude was much more common among children, while a utilitarian view of animals was far more typical of adults.

Some impressive attitude differences occurred among childiren distinguished by age, sex, ethnicity, and urban/rural residence.

Significant age differences were observed on every scale with the 
Table 5. National sample-18 years and older; childrens sample-2nd, 5 th, 8 th, 11 th grades by attitude scale mean scores, slope of scale frequency distribution, and rank of occurence

\begin{tabular}{lcccccc}
\hline & \multicolumn{3}{c}{ Adults } & & & \multicolumn{2}{c}{ Children } \\
& $\bar{X}$ & $\begin{array}{c}\text { Slope based on } \\
\text { actual response } \\
\text { ranges }\end{array}$ & $\begin{array}{c}\text { Rank of } \\
\text { occurence }\end{array}$ & $\bar{X}$ & $\begin{array}{c}\text { Slope based on } \\
\text { actual response } \\
\text { ranges }\end{array}$ & $\begin{array}{c}\text { Rank of } \\
\text { occurence }\end{array}$ \\
& & & & & & \\
\hline Dominionistic & .14 & -746.08 & 7 & .27 & -52.06 & 5 \\
Ecologistic & .22 & -603.25 & 5 & .27 & -61.60 & 5 \\
Humanistic & .36 & -359.86 & 1 & .43 & -17.09 & 1 \\
Moralistic & .27 & -375.90 & 3 & .33 & -37.05 & 4 \\
Naturalistic & .20 & -578.32 & 6 & .35 & -25.04 & 2 \\
Negativistic & .28 & -456.61 & 2 & .35 & -23.68 & 2 \\
Scientistic & .10 & -1143.45 & 8 & .23 & -76.67 & 8 \\
Utilitarian & .23 & -398.21 & 4 & .30 & -45.74 & 4 \\
\hline
\end{tabular}

exception of the humanistic (Table 6). Younger children consistently placed the needs of people over animals, and expressed minimal concern for the rights and protection of animals. This difference was reflected in highly significant utilitarian, dominionistic, and moralistic scale results. Younger children also expressed far less interest in animals, particularly wildlife. This difference was reflected in highly significant negativistic and naturalistic results. Finally, younger children were substantially less knowledgeable and informed about animals and the natural environment, as suggested by striking knowledge and ecologistic scale findings.

These results were somewhat surprising, perhaps due to our society's idealization of young children's perceptions of animals. The tendency is to believe young children have some natural affinity for living creatures, regarding them as little friends or kindred spirits. The results suggest otherwise, since young children were the most exploitative, unfeeling, and uninformed of all children in their attitudes toward animals. Some have argued our society creates a "make-believe" world for young children, often ill-preparing them for reality, and a related tendency may be a distortion of the actual views of young people toward animals. These results suggest educational efforts among children 6 to 10 years of age might best focus on the affective realm, mainly emphasizing emotional concern and sympathy for animals.

The most profound shift between 5 th and 8 th grade was a major 
Table 6. Analysis of variance and multiple classification analysis results for grade by attitude and knowledge scales

\begin{tabular}{|c|c|c|c|c|c|c|c|}
\hline & Sig F & $\begin{array}{c}\overline{\mathrm{X}} \\
\text { score }\end{array}$ & $\begin{array}{c}\text { Devia. from } \\
\text { mean after } \\
\text { adj. for ind. } \\
\& \text { cov. } \\
\text { variables }\end{array}$ & & Sig F & $\begin{array}{c}\overline{\mathrm{X}} \\
\text { score }\end{array}$ & $\begin{array}{l}\text { Devia. from } \\
\text { mean after } \\
\text { adj. for ind. } \\
\& \text { cov. } \\
\text { variables }\end{array}$ \\
\hline Dominionistic & .00 & & & Negativistic & .00 & & \\
\hline 2nd grade & & 4.65 & 1.71 & & & 8.79 & 2.87 \\
\hline 5th grade & & 3.26 & 0.24 & & & 6.29 & 0.12 \\
\hline 8th grade & & 1.96 & -1.35 & & & 5.12 & -0.87 \\
\hline 11th grade & & 2.12 & -0.56 & & & 4.04 & -1.98 \\
\hline Ecologistic & .00 & & & Scientistic & .00 & & \\
\hline 2nd grade & & 2.00 & -1.06 & & & 3.11 & 1.22 \\
\hline 5th grade & & 2.43 & -0.57 & & & 1.93 & 0.17 \\
\hline 8th grade & & 3.03 & 0.26 & & & 1.06 & -0.87 \\
\hline 11th grade & & 4.28 & 1.30 & & & 1.38 & -0.48 \\
\hline Humanistic & .67 & & & Utilitarian & .00 & & \\
\hline 2nd grade & & 4.37 & 0.16 & & & 4.20 & 0.86 \\
\hline 5 th grade & & 4.26 & -0.02 & & & 3.10 & -0.16 \\
\hline 8th grade & & 3.45 & -0.36 & & & 3.06 & -0.24 \\
\hline 11th grade & & 4.52 & -0.03 & & & 2.77 & -0.43 \\
\hline Moralistic & .01 & & & & & & \\
\hline 2nd grade & & 3.59 & -0.30 & & & & \\
\hline 5th grade & & 3.79 & -0.12 & & & & \\
\hline 8th grade & & 3.45 & -0.36 & & & & \\
\hline 11 th grade & & 4.71 & 0.74 & & & & \\
\hline Naturalistic & .01 & & & Knowledge & .00 & & \\
\hline 2nd grade & & 5.89 & 0.03 & & & 30.50 & -13.99 \\
\hline 5th grade & & 5.53 & -0.20 & & & 39.65 & -5.64 \\
\hline 8 th grade & & 5.18 & -0.83 & & & 51.18 & 7.45 \\
\hline 11 th grade & & 6.84 & 0.97 & & & 55.11 & 11.57 \\
\hline
\end{tabular}

The ages of children in the 2 nd, 5 th, 8 th and 11 th grades are (approximately): 6-7, 10,13 , and $16-18$ years, respectively.

increase in factual knowledge of animals. The apparent value of emphasizing factual learning at this age is consistent with results reported by Horvat (1974), Dyar (1975), La Hart (1978), and Giles (1959).

Eleventh graders were far more ecologistic, moralistic, and naturalistic in their attitudes toward animals than were 8th graders. Activity results also suggested 11 th grade children were far more interested in direct contact and recreational enjoyment of wildlife and the out-of-doors. The most basic change at this stage, thus, involved major increases in ethical concern for animals, appreciation of wildlife, and an ability to deal with abstract concepts such as ecosystems and biological diversity. This period appears to offer the best opportunity 
for developing ethical concern for animals and an understanding of ecology.

In summary, three major transitions were suggested by the results. The period from 2 nd to 5 th grade was most significantly characterized by a major increase in emotional concern and affection for animals. The years between 5 th and 8 th grades witnessed a dramatic improvement in factual and cognitive understanding of animals. Finally, the change from 8 th to 11 th grade was marked most of all by a major expansion in ethical and ecological concern for animals and the natural environment.

Highly significant differences among male and female children occurred on the dominionistic, ecologistic, humanistic, negativistic, and knowledge scales (Table 7). Moderately significant utilitarian scale results were also found. These results indicated greater factual knowledge, awareness and concern for wildlife among male children. On the other hand, female children were more inclined to oppose subordination and dominance of animals, and evidenced a greater emotional affection for large, attractive, primarily domestic pet animals.

Male/female differences on the humanistic, dominionistic and negativistic scales were significant at all age levels. Gender differences on

Table 7. Analysis of variance and multiple classification analysis results for sex by attitude and knowledge scales

\begin{tabular}{|c|c|c|c|c|c|c|c|}
\hline & Sig F & $\underset{\text { score }}{\bar{X}}$ & $\begin{array}{c}\text { Devia. from } \\
\text { mean after } \\
\text { adj. for ind. } \\
\& \text { cov. } \\
\text { variables }\end{array}$ & & Sig F & $\begin{array}{c}\bar{X} \\
\text { score }\end{array}$ & $\begin{array}{l}\text { Devia. from } \\
\text { mean after } \\
\text { adj. for ind. } \\
\& \text { cov. } \\
\text { variables }\end{array}$ \\
\hline Dominionistic & .00 & & & Negativistic & .00 & & \\
\hline Male & & 3.61 & 0.64 & & & 5.18 & -0.88 \\
\hline Female & & 2.34 & -0.62 & & & 6.80 & 0.85 \\
\hline Ecologistic & .01 & & & Scientistic & .89 & & \\
\hline Male & & 3.36 & 0.39 & & & 1.83 & -0.03 \\
\hline Female & & 2.60 & -0.38 & & & 1.86 & 0.03 \\
\hline Humanistic & .01 & & & Utilitarian & .09 & & \\
\hline Male & & 3.93 & -0.35 & & & 3.50 & 0.19 \\
\hline Female & & 4.65 & 0.34 & & & 3.06 & -0.19 \\
\hline Moralistic & .27 & & & & & & \\
\hline Male & & 3.73 & -0.16 & & & & \\
\hline Female & & 4.05 & 0.16 & & & & \\
\hline Naturalistic & .66 & & & Knowledge & .02 & & \\
\hline Male & & 5.78 & -0.13 & & & 47.03 & 2.47 \\
\hline Female & & 5.95 & 0.13 & & & 41.82 & -2.39 \\
\hline
\end{tabular}


the knowledge, ecologistic and moralistic scales, however, were inconsequential among 2nd grade children, although significant at all other age levels. An increase in moralistic concern among female students from 8th to 11th grades was particularly impressive. Male children, in contrast, became far more knowledgeable and concerned about wildlife and the natural environment than female children as they grew older.

Ethnic variations were striking on all the attitude scales with the exception of the moralistic and scientistic (Table 8). Far greater knowledge of animals and the natural enviroment among white children was particularly evident. Moreover, knowledge variations were as great in 2nd as 11th grade. Black children also expressed a greater willingness to subordinate animals, especially in the context of improving human material well-being. These differences were reflected in significant dominionistic and utilitarian scale results. Finally, black children revealed less affection and general interest in animals, particularly wildlife, as suggested by significant humanistic, negativistic, and naturalistic results.

Surprisingly few significant urban/rural differences were observed,

Table 8. Analysis of variance and multiple classification analysis results for ethnicity by attitude and knowledge scale

\begin{tabular}{|c|c|c|}
\hline Sig F & $\begin{array}{c}\overline{\mathrm{X}} \\
\text { score }\end{array}$ & $\begin{array}{l}\text { Devia. from } \\
\text { mean after } \\
\text { adj. for ind. } \\
\text { \& cov. } \\
\text { variables }\end{array}$ \\
\hline
\end{tabular}

$\begin{array}{ccc}\text { Sig } F & \bar{X} & \begin{array}{c}\text { Devia. from } \\ \text { score }\end{array} \\ & & \begin{array}{c}\text { mean after } \\ \text { adj. for ind. } \\ \text { \& cov. } \\ \text { variables }\end{array}\end{array}$

\begin{tabular}{|c|c|c|c|c|c|c|c|}
\hline Dominionistic & .01 & & & Negativistic & .00 & & \\
\hline White & & 2.74 & -0.25 & & & 5.58 & -0.16 \\
\hline Nonwhite & & 3.83 & 1.21 & & & 7.60 & 0.79 \\
\hline Ecologistic & .01 & & & Scientistic & .18 & & \\
\hline White & & 3.18 & 0.13 & & & 1.80 & -0.08 \\
\hline Nonwhite & & 2.12 & -0.66 & & & 2.19 & 0.39 \\
\hline Humanistic & .02 & & & Utilitarian & .01 & & \\
\hline White & & 4.41 & 0.19 & & & 3.13 & -0.16 \\
\hline Nonwhite & & 3.50 & -0.94 & & & 4.02 & 0.78 \\
\hline Moralistic & .39 & & & & & & \\
\hline White & & 3.91 & 0.03 & & & & \\
\hline Nonwhite & & 3.55 & -0.14 & & & & \\
\hline Naturalistic & .07 & & & Knowledge & .00 & & \\
\hline White & & 6.01 & 0.05 & & & 47.40 & 1.17 \\
\hline Nonwhite & & 5.05 & -0.22 & & & 31.60 & -5.72 \\
\hline
\end{tabular}


with the exception of negativistic and knowledge scale results (Table 9). Rural children were more interested and knowledgeable about animals, particularly in contrast to children living in the large cities. Few major changes occurred among residential groups when controlling for age. One exception was a marked increase in knowledge of animals among suburban children.

Table 9. Analysis of variance and multiple classification analysis results for population present residence by attitude and knowledge scales

\begin{tabular}{|c|c|c|c|c|c|c|c|}
\hline & Sig F & $\begin{array}{c}\overline{\mathrm{X}} \\
\text { score }\end{array}$ & $\begin{array}{c}\text { Devia. from } \\
\text { mean after } \\
\text { adj. for ind. } \\
\& \text { cov. } \\
\text { variables }\end{array}$ & & Sig F & $\begin{array}{c}\overline{\mathrm{X}} \\
\text { score }\end{array}$ & $\begin{array}{l}\text { Devia. from } \\
\text { mean after } \\
\text { adj. for ind. } \\
\text { \& cov. } \\
\text { variables }\end{array}$ \\
\hline Dominionistic & .24 & & & Negativistic & .04 & & \\
\hline Urban & & 3.04 & -0.48 & & & 6.75 & 0.61 \\
\hline Small city & & 3.34 & 1.15 & & & 5.85 & 0.41 \\
\hline Suburb & & 3.19 & -0.12 & & & 6.29 & -0.32 \\
\hline Rural & & 2.42 & -0.15 & & & 4.91 & -0.68 \\
\hline Ecologistic & .38 & & & Scientistic & .23 & & \\
\hline Urban & & 2.71 & -0.10 & & & 1.78 & 0.33 \\
\hline Small city & & 2.77 & -0.53 & & & 1.45 & -0.13 \\
\hline Suburb & & 3.11 & 0.42 & & & 2.06 & -0.05 \\
\hline Rural & & 3.35 & 0.10 & & & 2.03 & -0.15 \\
\hline Humanistic & .84 & & & Utilitarian & .69 & & \\
\hline Urban & & 4.15 & 0.18 & & & 3.39 & -0.12 \\
\hline Small city & & 4.49 & -0.01 & & & 3.15 & 0.20 \\
\hline Suburb & & 4.42 & -0.04 & & & 3.44 & 0.03 \\
\hline Rural & & 4.30 & -0.15 & & & 3.06 & -0.04 \\
\hline Moralistic & .43 & & & & & & \\
\hline Urban & & 3.92 & -0.08 & & & & \\
\hline Small city & & 4.23 & 0.30 & & & & \\
\hline Suburb & & 4.02 & 0.31 & & & & \\
\hline Rural & & 3.50 & -0.40 & & & & \\
\hline Naturalistic & .16 & & & Knowledge & .00 & & \\
\hline Urban & & 5.47 & -0.49 & & & 38.00 & -5.96 \\
\hline Small city & & 5.72 & -0.09 & & & 46.90 & -1.13 \\
\hline Suburb & & 5.79 & -0.06 & & & 42.90 & 2.52 \\
\hline Rural & & 6.61 & 0.67 & & & 52.30 & 5.23 \\
\hline
\end{tabular}

Attitude differences observed across all the demographic groups additionally revealed some interesting results, although these will be only briefly examined. On the negativistic scale, the highest scores were found among 2nd graders, nonwhites, female and urban children, 
in contrast to the low scores of 8 th and 11 th grade, rural resident, and male children (Figure 2). Ecologistic scores were highest among older children, male, and rural residents, in comparison to the low scores of 2nd graders and nonwhites (Figure 3). On the utilitarian scale, 2nd

Figure 2: Negativistic scale mean scores by children demographic groups

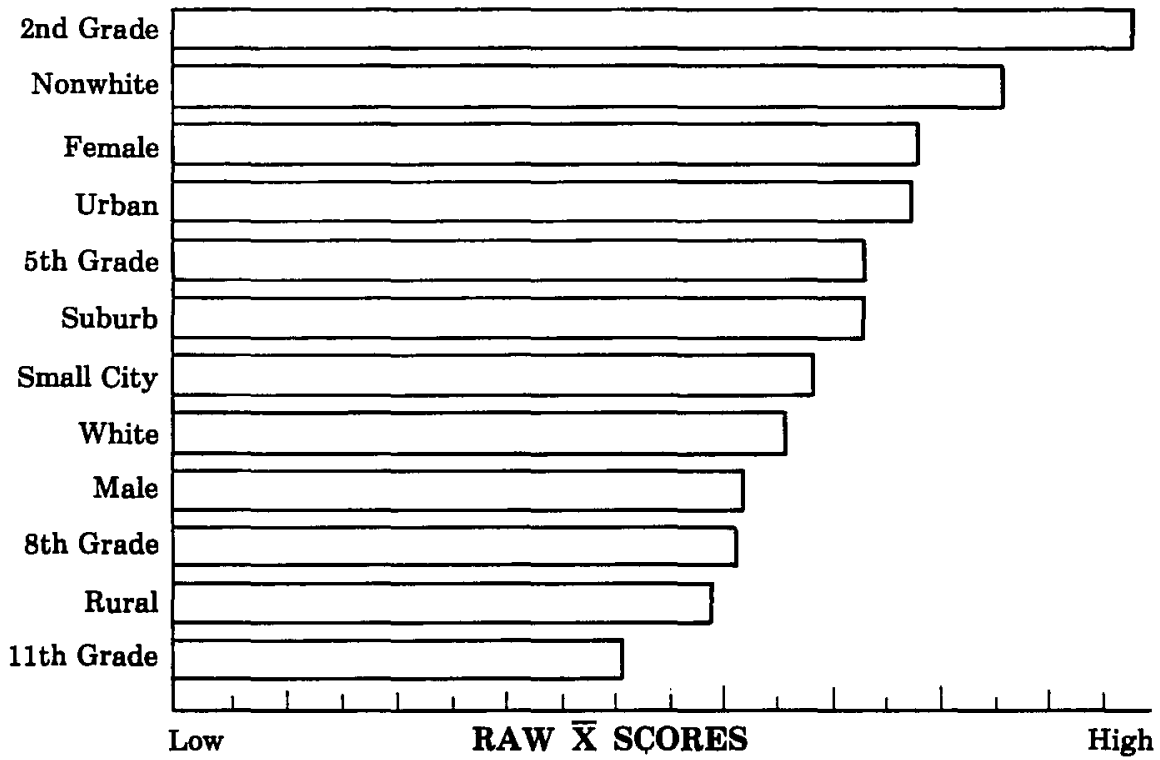

Figure 3: Ecologistic scale mean scores by children demographic groups

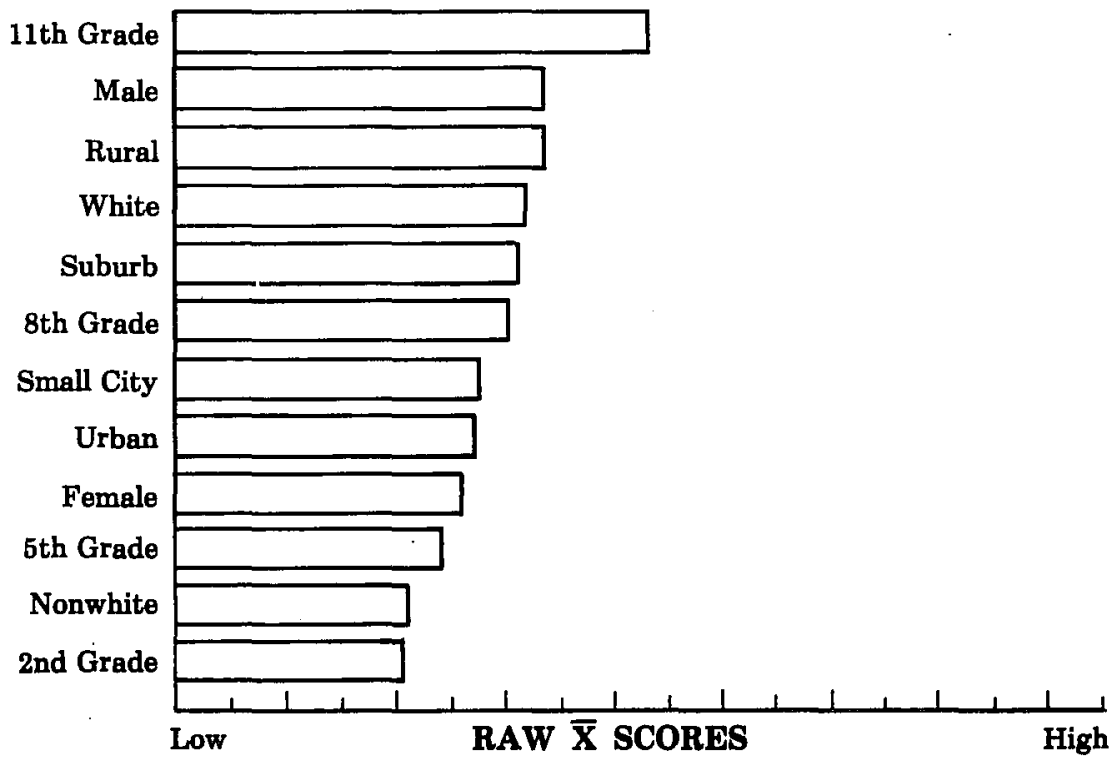


graders and nonwhites had the highest scores, while the lowest utilitarian scores occurred among 11th graders and female children (Figure 4).

Figure 4: Utilitarian scale mean scores by children demographic groups

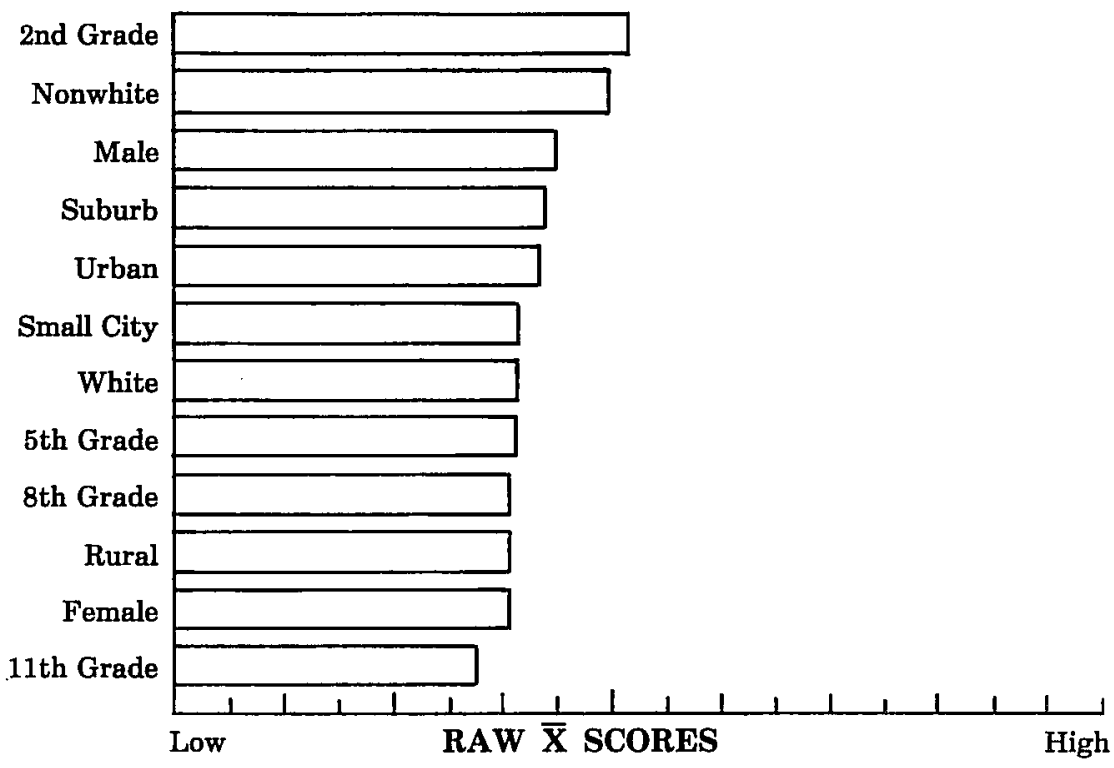

\section{ACTIVITIES}

The extent and influence of various activities involving animals will be briefly reviewed. Three-quarters or more of the children participated in seven animal-related activities during the previous twoyear period including visiting zoos $(93 \%)$, owning a pet $(87 \%)$, fishing $(87 \%)$, learning about animals in schools $(83 \%)$, feeding birds $(82 \%)$, reading books or magazines about animals $(76 \%)$, and watching "Wild Kingdom" on television (74\%). On the other hand, the least frequent activities included family livestock raising $(21 \%)$, hunting $(18 \%)$, trapping (13\%), and belonging to an animal-related club $(8 \%)$.

The attitude and knowledge scores of children who frequently participated in some of these activities were examined. Particularly surprising was the relatively low knowledge scores of children who learned about animals in school or who visited zoos (Table 10). Moreover, these two groups had the highest negativistic scale scores (Table 11). These activities, thus, appeared to exert little positive influence on children. Most zoological parks continue to fail to go beyond superficial entertainment toward instilling greater appreciation of animals among children, while most learning about animals in school appears to be so di- 
Table 10. Knowledge scale mean scores by selected animal activity groups*

Mean score

Ever hunted

51.77

Belong to animal club

51.23

Family raised livestock

Went outside to look at birds

45.85

Have a pet

45.63

Learned about animals in school

Went to zoo

44.89

*Most of these groups include only children who frequently participated in these activities. Significance tests were not performed because the groups were not mutually exclusive.

Table 11. Negativistic scale mean scores by selected animal activity groups

Mean score

Went to zoo

5.94

Learned about animals in school

5.92

Went outside to look at birds

5.88

Ever fished

5.75

Family raised livestock

5.65

Have a pet

5.46

Belong to animal club

5.18

Ever hunted

3.89

vorced from direct experience with animals and the natural environment that little basic knowledge results.

More encouraging activity results were found among children who birdwatched, belonged to animal-related clubs, or hunted. These children were generally more appreciative, knowledgeable, and concerned about animals. These results suggest the positive value of direct, participatory contact between children and animals.

\section{CONCLUSION}

Perhaps the most outstanding result of this exploratory study was the indication of varying stages in the evolution of children's percep- 
tions of animals. Each period appears to offer varying opportunities for environmental education. The transition from 2 nd to 5 th grade would seem the most opportune time for emphasizing affective/emotional concern for animals. The interval between 5 th and 8 th grades, on the other hand, offers the most promising possibilities for developing cognitive and factual understanding of animals. Finally, the shift from 8th to 11th grades would appear to be the most appropriate period for fostering ethical and ecological appreciation of animals and the natural world.

Ethnic and urban/rural findings suggest the need for devoting more attention to the animal-related perceptions and interests of urban disadvantaged children. Activity results indicate the value of educational programs that emphasize direct contact and experimental involvement with animals.

The results of this exploratory study clearly suggest the importance of more extensive and in-depth investigation of children's perceptions and relationships to animals. The reported findings intimate the possibility of exercising meaningful influence on the development of a more positive, informed, and benign perspective on animals among children. More ambitious and imaginative efforts will be required, however, as the eventual well-being of animals and the natural world will depend on the future commitment and concern of today's youth. 


\section{REFERENCES}

Dyar, N.A. 1975. Assessing environmental attitudes and behaviors of a seventh grade population. Ph.D. dissertation. Berkeley: University of California.

Giles, R.H. Jr. 1959. The conservation knowledge of Virginia school pupils. Transactions North American Wildlife Natural Resource Conference, 29:488-97.

Horvat, R.E. 1974. Fifth and eighth grade student orientation toward the environment and environmental problems. Ph.D. dissertation, University of Wisconsin.

Kellert, S.R. 1979. Public attitudes toward critical wildlife issues. Order from U.S. Government Printing Office, Number 024-020-00-623-4, Washington, D.C.

Kellert, S.R. 1980a. Activities of the American public relating to animals. Order from U.S. Government Printing Office, Number 024-010-00-624-2, Washington, D.C.

Kellert, S.R. 1980b. Contemporary values of wildlife in American society. In: Shaw, W.W. and Zube, E.H. eds. Wildlife Values. Center for Assessment of Noncommodity Natural Resource Values, Institutional Series Report Number 1. U.S.D.A., Rocky Mountain Forest and Range Experiment Station, Fort Collins, Colorado, pages 31-60.

Kellert, S.R. and Berry, J.K. 1981. Knowledge, affection and basic attitudes towards animals in American society. Order from U.S Government Printing Office, Number 024-010-00-625-1, Washington, D.C.

Kellert, S.R. and Westervelt, M.O. 1982. Trends in animal use and perceptions in 20th century America. Order from U.S. Government Printing Office, Number 024020-006-21-8, Washington, D.C.

LaHart, D.E. 1978. The influence of knowledge on young people's perceptions about wildlife. Final report to National Wildlife Federation, Washington, D.C.

Pomerantz, G.A. 1977. Young peoples attitudes toward wildlife. Division report number 2781, Michigan Department Natural Resources. 